\title{
OPTICALLY INDUCED CURRENT DEEP LEVEL SPECTROSCOPY OF RADIATION DEFECTS IN NEUTRON IRRADIATED Si PAD DETECTORS
}

\author{
E. Gaubas, D. Bajarūnas, T. Čeponis, D. Meškauskaitė, and J. Pavlov \\ Institute of Applied Research, Vilnius University, Saulètekio 9-III, LT-10222 Vilnius, Lithuania \\ E-mail: eugenijus.gaubas@ff.vu.lt
}

Received 6 August 2013; accepted 4 December 2013

\begin{abstract}
Identification of the prevailing radiation defects of large density remains a considerable issue for particle detectors made of high resistivity Si. To clarify the dominant radiation induced traps within CERN standard Si pad detectors, the capacitance (C-) and current (I-) deep level transient spectroscopy (DLTS) techniques have been combined. Additionally, the optical (O-) injection I-DLTS regime has been employed to cover a wide range of neutron irradiation fluences of $10^{12}-10^{16} \mathrm{~cm}^{-2}$. The spectra of C-DLTS and O-I-DLTS have been recorded using the temperature scans in the range of $20-300 \mathrm{~K}$. The radiation induced vacancy $(\mathrm{V})$ attributed defects such as $\mathrm{V}-\mathrm{O}, \mathrm{V}_{2}$, and clusters have been identified, the density of which increases with irradiation fluence in the range of $10^{12}-10^{14} \mathrm{~cm}^{-2}$, while this density saturates for the collected neutron fluence of more than $10^{14} \mathrm{~cm}^{-2}$.
\end{abstract}

Keywords: C-DLTS, I-DLTS, O-I-DLTS, Si particle detectors, neutron irradiation

PACS: 72.40.+w, 29.40.-n, 78.60.-b

\section{Introduction}

Si based particle detectors are commonly made of high purity and large resistivity material [1]. These detectors should be radiation tolerant up to an extremely large fluence of $10^{16} \mathrm{~cm}^{-2}$. However, the effective doping density $N_{\text {eff }}$ of the material varies during detector operation due to charged radiation defects inevitably introduced. As a result, the charge collection efficiency, being the most important characteristic of detector functionality, is reduced [2].

To predict changes of detector parameters, it is necessary to control the spectra of the introduced radiation defects. The standard and widely used spectroscopy technique is the capacitance deep level transient spectroscopy (C-DLTS) which is a sufficiently sensitive and straight spectroscopy technique for characterization of deep radiation traps [3]. However, the standard application of C-DLTS is limited by the trap concentration, which should not be larger than the doping density [4]. The measurement of generation current (I-DLTS) is an option of the DLTS tech- nique, which can be approved for the spectroscopy of high density carrier traps in silicon detectors made of large resistivity material [5]. An electrical filling of deep traps by manipulating the carrier injection pulses exploited in standard DLTS techniques can be inefficient for the radiation affected junction of the detectors. Therefore, an additional modification of DLT spectroscopy is implemented by using an optical carrier injection leading to the optical current DLTS (O-I-DLTS) regime [4]. Optical excitation employing the laser or LED light illumination fills both types of the majority and minority carrier traps. However, it is impossible to distinguish the current components ascribed to the majority and minority carrier traps within the generation current transients. This is a disadvantage for usage of O-I-DLTS [ 6 .

In this study, C-DLTS and O-I-DLTS techniques have been combined to identify the prevailing radiation traps and to cover a wide range of the trap and effective doping densities. A set of reactor neutron irradiated $\mathrm{Si}$ detectors covering the fluence range from $10^{12}$ to $10^{16} \mathrm{n} / \mathrm{cm}^{2}$ was examined. The radiation 
induced vacancy attributed defects such as $\mathrm{V}-\mathrm{O}$, $\mathrm{V}_{2}$, and clusters have been identified, the density of which increases with irradiation fluence in the range of $10^{12}$ to $10^{14} \mathrm{~cm}^{-2}$, while this density saturates for the collected neutron fluence of more than $10^{14} \mathrm{~cm}^{-2}$.

\section{Samples and measurement regimes}

The standard CERN pad detectors made of the $n$-type magnetic Czochralski (MCZ) Si were examined. A window of about $2 \mathrm{~mm}$ in diameter in the centre of the detector metallic electrode is left non-metalized [7], 8] for optical excitation. A set of the same detectors was irradiated by reactor neutrons varying fluence from $10^{12}$ to $10^{16} \mathrm{~cm}^{-2}$.

The different regimes of DLT spectroscopy have been implemented using a HERA-DLTS System 1030 spectrometer. The temperature scans are performed in the range of 20-300 K using a closed-cycle He cryostat. The temperature sensors are connected to a LakeShore temperature control device. The barrier capacitance transients are directly recorded by using a Boonton capacitance meter when implementing the C-DLTS mode. This capacitance meter is connected to the basic unit of the spectrometer. The basic unit is equipped with a voltage source, a low pass filter, an amplifier, and a current meter. A reverse bias is commonly set at $10 \mathrm{~V}$, and the electrical injection pulse of voltage of $0.5 \mathrm{~V}$ and duration of $0.1 \mathrm{~s}$ is as usual kept. The I-DLTS mode is implemented by using a current meter installed within the basic module of the spectrometer. The O-I-DLTS regime has been implemented by using optical 20 ms injection pulses generated by an yttrium aluminium garnet neodymium (Nd:YAG) laser at $1064 \mathrm{~nm}$ wavelength. All the measurement and data processing procedures are controlled by a personal computer equipped with PhysTech software.

\section{Deep level spectra}

The C-DLTS temperature scan spectra have been examined on a Si particle detector irradiated with a neutron fluence of $10^{12} \mathrm{~cm}^{-2}$ to separate traps of majority and minority carriers. The recorded spectrum is illustrated in Fig. 1 .

For diodes irradiated with the larger neutron fluence it is impossible to record a spectral structure using C-DLTS due to the introduced trap density which exceeds that of doping. A weak nearly invariable signal

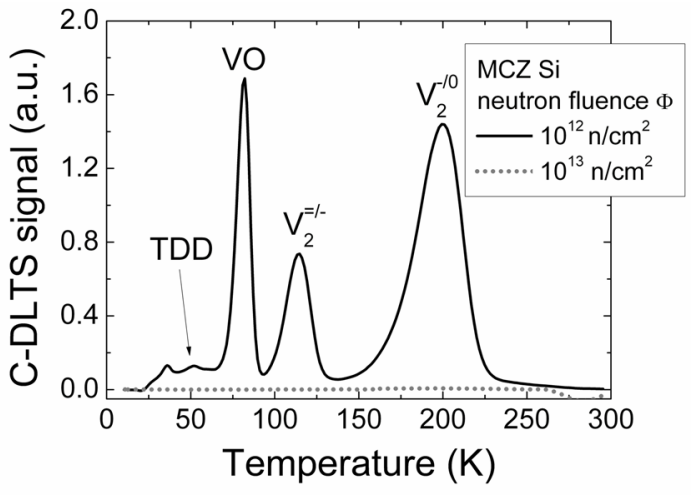

Fig. 1. C-DLTS spectra of the detector irradiated with a neutron fluence of $10^{12} \mathrm{n} / \mathrm{cm}^{2}$ compared with the C-DLTS signal for the detector irradiated with a fluence of $10^{13} \mathrm{n} / \mathrm{cm}^{2}$.

of barrier capacitance can only be detected for a diode irradiated with a neutron fluence of $10^{13} \mathrm{~cm}^{-2}$ as illustrated in Fig. 1. This happens due to a decrease of barrier capacitance and synchronous increase of leakage current. Then, it is impossible to govern the irradiated junction structure by a small harmonic test signal due to the enhanced generation/leakage current, which yields an inappropriate reduction of the quality factor in a Boonton capacitance meter.

Thereby, the C-DLTS analysis of radiation defects was only possible for the diodes irradiated with a neutron fluence of $10^{12} \mathrm{~cm}^{-2}$. The Arrhenius plots are commonly employed to extract the capture cross-section $\sigma$, activation energy $E_{\mathrm{A}}$, and trap density parameters for the definite defect responsible for the appeared peak in the C-DLTS temperature scan spectrum. Each radiation trap has been identified by comparing the DLTS signatures $\left(T_{\text {peak }}, \sigma, E_{\mathrm{A}}\right)$ extracted from the Arrhenius plots with the defect signature library data integrated within the PhysTech interface of a HERA-DLTS System 1030 spectrometer. The dominant majority carrier traps (denoted in Fig. 1) have been identified as follows: the C-DLTS peak at about $50 \mathrm{~K}$ is attributed to the dual thermal donor (TDD), the peak at $95 \mathrm{~K}$ is ascribed to the oxygen-vacancy complex $(\mathrm{V}-\mathrm{O})$, and the peaks at 120 and $210 \mathrm{~K}$ are associated with the double-charged $\left(\mathrm{V}_{2}^{=/-}\right)$and singlecharged $\left(\mathrm{V}_{2}^{-10}\right)$ divacancy, respectively. The minority carrier traps are mainly associated with the formation of a complex of interstitial impurities of $\mathrm{C}_{\mathrm{i}}$ and $\mathrm{O}_{\mathrm{i}}$.

The O-I-DLTS spectra recorded on the diodes irradiated with neutron fluences in the range of $10^{13}-10^{16} \mathrm{~cm}^{-2}$ are shown in Fig. 2. In these spectra, the traps identified by the C-DLTS technique (Fig.1), 
namely TDD, $\mathrm{V}-\mathrm{O}$, and $\mathrm{V}_{2}$, are resolved. Additionally, the O-I-DLTS peaks at $170 \mathrm{~K}$ and at $>300 \mathrm{~K}$ appear for the diodes irradiated with a neutron fluence $\geq 10^{15} \mathrm{~cm}^{-2}$. The appearance of additional deep traps (denoted as $E_{4}$ and $E_{6}$ in Fig. 2) is in agreement with results obtained by alternative spectroscopy techniques applied on the same irradiated diodes using temperature scans of generation current and instantaneous carrier trapping lifetime [7]. The trivial interpretation of the $E_{4}$ peak using the PhysTech library would lead to its attribution to the $\mathrm{C}_{\mathrm{i}}-\mathrm{O}_{\mathrm{i}}$ complex with the mentioned uncertainty, when traps of the majority and minority carriers cannot be distinguished by the I-DLTS technique. However, the origin of the trap which is responsible for the appearance of the peak at $170 \mathrm{~K}$ is debated in literature [8]. The clear formation of the $E_{6}$ peak at $>300 \mathrm{~K}$ cannot be resolved by using the HERA-DLTS System 1030 spectral instrument.

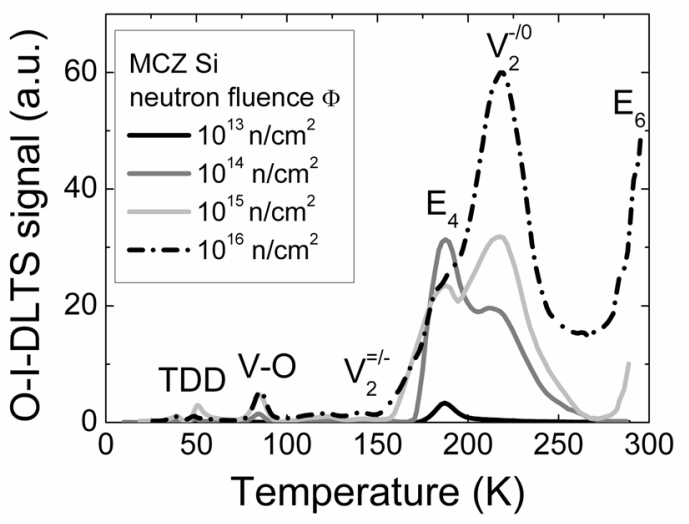

Fig. 2. O-I-DLTS spectra of samples irradiated with reactor neutrons of different fluencies.

\section{Discussion}

The peak amplitude in the C-and O-I-DLTS spectra represents roughly the density of the definite type traps. The fluence dependent variation of density of the traps, which can be resolved over the entire range of irradiation fluences, is represented in Fig. 3 .

It can be deduced from Fig. 3 that density of all the observed radiation traps increases near- linearly in the range going from the smallest fluences up to a fluence value of $10^{14} \mathrm{~cm}^{-2}$. The values of the trap density start to saturate for the $\mathrm{V}-\mathrm{O}$ and $\mathrm{V}_{2}$ radiation defects in the fluence range of $>10^{14} \mathrm{~cm}^{-2}$. The density of $E_{4}$ type traps saturates for even smaller fluences, while the density of TDD defects varies non-mo- notonically relative to the fluence scale. The density of $E_{6}$ type traps, as deduced from the changes of the peak amplitude (Fig. 2), increases even faster than the density of divacancies with the enhancement of neutron fluence in the range of $\geq 10^{15} \mathrm{~cm}^{-2}$.

The V-O defect (known as the A-centre within the DLTS nomenclature) is the most investigated radiation induced complex [9]. Changes of the relative amplitudes of TDD and V-O peaks within the O-I-DLTS spectra clearly indicate the creation of the vacancy associated complexes through the radiation induced vacancy migration. Incorporating of the isovalent impurities, such as Ge, may considerably suppress the formation of $\mathrm{V}-\mathrm{O}$ centres, and the TDD density prevails then over the density of $\mathrm{V}-\mathrm{O}$ complexes [10].

The amplitude of the DLTS peak at 170-190 K also saturates, which might be related to the interstitial impurity complexes $\mathrm{C}_{\mathrm{i}} \mathrm{O}_{\mathrm{i}}[11]$ acting as the hole traps. On the other hand, this peak can be ascribed to the inter-centre interplay [8] or multi-vacancy complexes with oxygen [12, 13]. These latter defects can also be ascribed to vacancy clusters [8]. The single-charged divacancies $\mathrm{V}_{2}^{-/ 0}$ seem to be the most stable vacancy complexes [14], the density of which saturates only in the range of the highest neutron fluences. The observed changes of the $E_{4}$ and $\mathrm{V}_{2}^{-/ 0}$ deep centre density can be understood as a result of vacancy migration mediated reactions of the non-equilibrium radiation defects.

The deepest centre $E_{6}$ can be ascribed to the cluster type defects which introduce the mid-gap levels. These defects are the most efficient carrier killers [15], which affect the operational characteristics of the detectors.

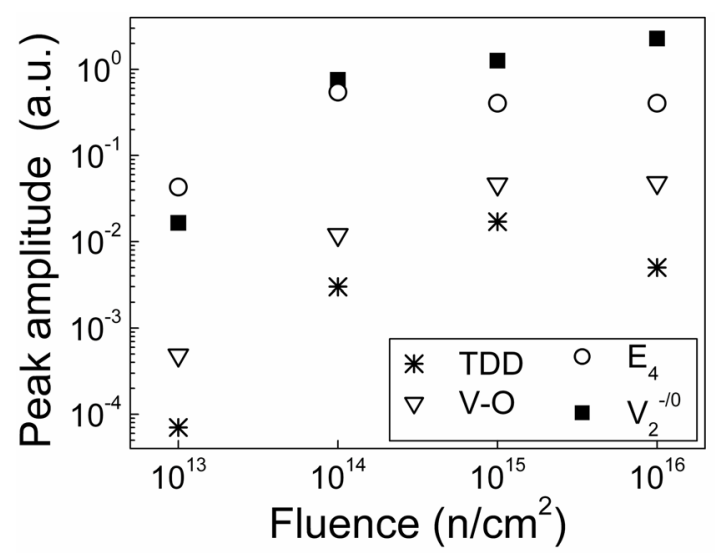

Fig. 3. Dependence of the amplitude of O-I-DLTS spectral peaks on neutron irradiation fluence obtained for MCZ Si detectors. 


\section{Summary}

The neutron fluence dependent variation of radiation defect spectra in MCZ Si pad detectors has been examined by combining C-DLTS and O-I-DLTS regimes. The TDD, $\mathrm{V}-\mathrm{O}$, and $\mathrm{V}_{2}$ ascribed peaks have been observed within C-DLTS spectra measured in diodes irradiated with a fluence of $10^{12} \mathrm{n} / \mathrm{cm}^{2}$. Up to six O-I-DLTS peaks have been resolved within the temperature scan spectra measured in the range of 20-300 K. These DLTS peaks have been ascribed to the TDD, $\mathrm{V}-\mathrm{O}, \mathrm{V}_{2}$, and multi-vacancy complexes. The radiation induced vacancy attributed defects such as $\mathrm{V}-\mathrm{O}, \mathrm{V}_{2}$, and clusters have been identified, the density of which increases with irradiation fluence in the range of $10^{12}-10^{14} \mathrm{~cm}^{-2}$, while this density saturates for the collected neutron fluence of more than $10^{14} \mathrm{~cm}^{-2}$.

\section{Acknowledgements}

This study has been supported by the Research Council of Lithuania, grant MIP-060/2013.

\section{References}

[1] G. Lindstrom, I. Dolenc, E. Fretwurst, F. Honniger, G. Kramberger, M. Moll, E. Nossarzewska, I. Pintilie, and R. Roder, Epitaxial silicon detectors for particle tracking, - radiation tolerance at extreme hadron fluence, Nucl. Instrum. Methods A 568, 66-71 (2006).

[2] I. Pintilie, E. Fretwurst, and G. Lindstrom, Cluster related hole traps with enhanced-field-emission the source for long term annealing in hadron irradiated Si diodes, Appl. Phys. Lett. 92, 024101 (2008).

[3] D.V. Lang, Deep-level transient spectroscopy: a new method to characterize traps in semiconductors, J. Appl. Phys. 45, 3023 (1974).

[4] P. Blood and J.W. Orton, The Electrical Characterization of Semiconductors: Majority Carriers and Electron States (Academic Press Inc., San Diego, 1992).
[5] A.U. Pandey, P. Middelkamp, Z. Li, and V. Eremin, New experimental and analysis methods in I-DLTS, Nucl. Instrum. Methods A 426, 109-113 (1999).

[6] Z. Li, Systematic modelling and comparisons of capacitance and current-based microscopic defect analysis techniques for measurements of highresistivity silicon detectors after irradiation, Nucl. Instrum. Methods A 403, 399-416, (1998).

[7] E. Gaubas, T. Ceponis, J. Pavlov, A. Velička, and V. Kalesinskas, Spectroscopy of radiation traps by techniques of temperature dependent photoconductivity and generation currents in neutron irradiated Si, submitted to Lith. J. Phys. (2013).

[8] K. Gill, G. Hall, and B. MacEvoy, Bulk damage effects in irradiated silicon detectors due to clustered vacancies, J. Appl. Phys. 82, 126-136 (1997).

[9] S. Yang, Y. Li, Q. Ma, L. Liu, X. Xu, P. Niu, Y. Li, S. Niu, and $\mathrm{H}$. Li, Infrared absorption spectrum studies of the VO defect in fast-neutron-irradiated Czochralski silicon, J. Cryst. Growth 280, 60-65 (2005).

[10] E. Gaubas, A. Uleckas, J.M. Rafi, J. Chen, D. Yang, and J. Vanhellemont, Study of irradiation induced changes of electrical and functional characteristics in Ge doped Si diodes, Physica B 407, 2998 (2012).

[11] M. Moll, E. Fretwurst, M. Kuhnke, and G. Lindstrom, Relation between microscopic defects and macroscopic changes in silicon detector properties after hadron irradiation, Nucl. Instrum. Methods B 186, 100-110 (2002).

[12] J.L. Lindstrom, L.I. Murin, B.G. Svensson, V.P. Markevich, and T. Hallberg, The $\mathrm{VO}_{2}^{*}$ defect in silicon, Physica B 340-342, 509-513 (2003).

[13] L.I. Murin, B.G. Svensson, J.L. Lindstrom, V.P. Markevich, and C.A. Londos, Trivacancy-oxygen complex in silicon: local vibrational mode characterization, Physica B 404, 4568-4571 (2009).

[14] V. Eremin, A. Ivanov, E. Verbitskaya, Z. Li, and S.U. Pandey, Analysis of divacancy related traps induced by proton, neutron and gamma radiation in high resistivity silicon detectors, Nucl. Instrum. Methods A 426, 120-125 (1999).

[15] M. Huhtinen, Simulation of non-ionizing energy loss and defect formation in silicon, Nucl. Instrum. Methods A 491, 194-215 (2002).

\title{
NEUTRONAIS APŠVITINTŲ Si DETEKTORIŲ RADIACINIŲ DEFEKTŲ GILIŲJŲ LYGMENŲ OPTIŠKAI ŽADINAMOS SROVĖS SPEKTROSKOPIJA
}

\author{
E. Gaubas, D. Bajarūnas, T. Čeponis, D. Meškauskaitė, J. Pavlov \\ Vilniaus universiteto Taikomujų mokslu institutas, Vilnius, Lietuva
}

\section{Santrauka}

Darbe analizuotos giliosios krūvininkų gaudyklès, susiformavusios CERN standarto Si detektoriuose po apšvitos greitaisiais neutronais varijuojant ịtèkị $10^{12}-10^{16} \mathrm{~cm}^{-2}$ intervale. Giliujų lygmenų parametrai ịvertinti pasitelkus giliujų lygmenų talpinį (C-DLTS) ir giliụjų lygmenų optiškai žadinamos generacinès srovès (O-I-DLTS) temperatūrinès žvalgos metodus. C-DLTS ir O-I-DLTS spektruose identifikuoti radiaciniai defektai. Paaiškejjo, kad didelių ịtẻkių srityje vyrauja apšvita sukurtos divakansijos ir sankaupiniai defektų kompleksai. Aptikta, jog generacinių centrų tankio augimas îsisotina ties $10^{14} \mathrm{n} / \mathrm{cm}^{-2}$. 